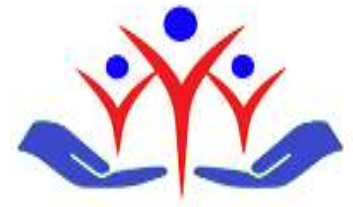

Family Practice and Palliative Care

d

Case Report

\title{
Methemoglobinemia after local anesthetic (prilocaine) application: a case report
}

\section{Lokal anestezik (prilokain) uygulamasına bağlı gelişen methemoglobinemi: Olgu sunumu}

(Dulsen Yalcin ${ }^{\mathrm{a}}$, (D) Onder Kilicaslan ${ }^{\mathrm{b}}$, (D) Aybars Ozkan ${ }^{\mathrm{c}}$, (D) $_{\text {Kan Kocabay }}{ }^{\mathrm{b}}$

${ }^{a}$ Duzce University, School of Medicine, Department of Pediatric Emergency, Duzce, Turkey

${ }^{b}$ Duzce University, School of Medicine, Department of Pediatrics, Duzce, Turkey

${ }^{c}$ Duzce University, School of Medicine, Department of Pediatric Surgery, Duzce, Turkey

\begin{abstract}
Introduction: Circumcision is a surgical procedure performed by many societies for religious, medical and cultural purposes. One of the agents used during this procedure is prilocaine, a commonly used local anesthetic. In the literature, cases of methemoglobinemia which can be developed with the application of prilocaine in normal dose have been reported. Oxidation of hemoglobin with various oxidative stresses is called methemoglobinemia when the divalent iron in its content is converted into its trivalent form. This reaction

leads to hypoxaemia in the tissue and a clinical picture of cyanosis occurs at varying degrees.

Case Report: Two-and-a-half-month-old patient was referred to my hospital by a physician because of the complaint of bruising after local anesthesia with prilocaine and the measured oxygen saturation was $79 \%$. Physical examination revealed cyanosis in the peroral region, hands and feet. It was decided that methylene blue should be administered considering the fact that the patient was given prilocaine as a local anesthetic, due to the inability to find an underlying respiratory and cardiac cause, and because of the high value of methemoglobin in blood gas. Methylene blue $2 \mathrm{mg} / \mathrm{kg}$ was given orally. About an hour later, cyanosis disappeared. The control methhemoglobin level was found to be $2.7 \%$.

Conclusion: Methemoglobinemia should be considered in the differential diagnosis of cyanosis after local anesthetic application and local anesthetics with less side effects should be preferred in early infancy. In this case report, it was aimed to discuss the differential diagnosis and treatment methods of methemoglobinemia after local anesthesia with prilocaine.
\end{abstract}

Keywords: Methemoglobinemia, local anesthetics, prilocaine, circumcision

\section{ÖZ}

Giriş: Sünnet, pek çok toplum tarafından dini, tıbbi ve de kültürel amaçlarla yapılan cerrahi işlemdir. Bu işlem esnasında kullanılan ajanlardan birisi olan prilokain sık kullanılan bir lokal anestezik ilaçtır. Literatürde normal dozda prilokainin uygulaması ile gelişebilen methemoglobinemi vakaları bildirilmiştir. Hemoglobinin çeşitli oksidatif streslerle oksitlenmesi sonucu, içeriğindeki iki değerli demirin, üç değerli haline dönüşmesine methemoglobinemi denir. Bu reaksiyon, dokuda hipoksemiye yol açar ve değişen derecelerde siyanozla kendini gösteren klinik tablo oluşur.

Olgu Sunumu: İki buçuk aylık olgu, prilokain ile lokal anestezi uygulaması sonrası ortaya çıkan morarma şikayeti ve ölçülen oksijen satürasyonu \%79 olması nedeniyle hastanemize doktor tarafindan sevki yapıldı. Geliş fizik muayenesinde peroral bölgede, el ve ayaklarda siyanozu vardı. Hastaya lokal anestezik olarak prilokain verildiğinin öğrenilmesi, altta yatan solunumsal ve kardiyak bir nedenin bulunamaması ve kan gazında methemoglobin değerinin yüksekliği nedeniyle, ilaca bağlı methemoglobinemi düşünülerek metilen mavisi verilmesine karar verildi. Metilen mavisi 2 mg/kg oral verildi. Yaklaşık bir saat sonra siyanoz kayboldu. Kontrol methemoglobin düzeyi \%2,7 olarak saptand1.

Sonuç: Lokal anestezik uygulaması sonrası gelişen siyanozun ayırıcı tanısında methemoglobinemi mutlaka düşünülmeli ve erken süt çocukluğu döneminde yan etkileri daha az olan lokal anestezikler tercih edilmelidir. Bu olgu sunumunda prilokain ile lokal anestezi uygulaması sonrası ortaya çıkan methemoglobinemide ayırıcı tanı ve tedavi yöntemlerinin tartışılması amaçlandı.

Anahtar Kelimeler: Methemoglobin, lokal anestezik, prilokain, sünnet

Submission: Aug 25, 2017

Acceptance: Nov 16, 2017

E-mail: drgyalcin@gmail.com

Correspondence: Gulsen Yalcin, MD

Duzce University, School of Medicine, Department of Pediatric Emergency, Duzce, Turkey 


\section{Giriș}

Siyanoz, çocuklarda hızlı tetkik ve tedavi işlemlerini gerektiren bir durumdur. Kapiller düzeyde redükte hemoglobin miktarının $5 \mathrm{gr} / \mathrm{dl}$ 'yi aşması sonucu gelişir. Hemoglobin $(\mathrm{Hb})$ eritrositlerde bulunan ve dokulara oksijen $\left(\mathrm{O}_{2}\right)$ taşınmasını sağlayan bir moleküldür. Normal koşullarda Hb'de bulunan demir iki değerlidir $\left(\mathrm{Fe}^{++}\right)$ve Hb'deki demirin okside olup, üç değerli $\left(\mathrm{Fe}^{+++}\right)$duruma geçmesiyle methemoglobinemi gelişir [1]. Methemoglobin $\mathrm{O}_{2}$ taşıyamaz ve hemoglobin-oksijen dissosiasyon eğrisini sola kaydırarak dokulara daha zor $\mathrm{O}_{2}$ verilmesine yol açar. Bu fonksiyonel olmayan hemoglobin, dokuda hipoksemiye yol açar. Oksidasyon ve redüksiyon arasındaki dengenin bozulması methemoglobinemi gelişimine sebep olur. Fizyolojik şartlarda methemoglobin total Hb'nin \%1'i kadardır. Sağlıklı bireylerde oksidan maddelerle temas sonucu methemoglobin oluşur. Ancak eritrosit içi methemoglobin indirgeyici sistem (sitokrom-b5 redüktaz enzim sistemi) tarafından konsantrasyonu \%2'nin altında tutulur. Sağlıklı ve anemisi olmayan bireylerde akut olarak \%20-30'a kadar yükselmeler iyi tolere edilir. Methemoglobin düzeyi \%35'in üstüne çıktığında doku hipoksisi sonucu halsizlik, taşikardi, solunum sıkıntısı, bulantı-kusma gibi sistemik semptomlar, \%55'in üzerinde letarji, stupor ve senkop gelişir. Düzey \%70'in üstünde ise fatal seyirlidir [2]. Bu yazıda sünnet öncesi prilokain uygulamasına bağlı gelişen ve takibinde destek tedavisi ile düzelen bir methemoglobinemi olgusu sunulmuştur.

\section{Olgu sunumu}

İki buçuk aylık erkek hastaya ailenin isteği ile devlet hastanesinde, lokal prilokainle dorsal penil blok ve takibinde sünnet operasyonu yapılmış. Sonrasında ilk bir saatte sorun olmamış ancak ikinci saatte dudaklarda siyanoz saptanmış ve ölçülen oksijen satürasyonu \%79 saptanmış. Hasta ileri tetkik ve tedavi amacıyla hastanemiz çocuk acil servisine kabul edildi. Annenin ikinci hamileliğinden miadında, 3860 gram ağırlığında normal spontan doğum ile doğan, anne sütü ile beslenen erkek olgunun doğum öncesi ve sonrasında özellik yoktu. Ayrıntılı soygeçmiş incelemesinde özellik saptanmadı. Geliş fizik muayenesinde peroral bölgede, el ve ayaklarda siyanozu vardı. Ateşi $37^{\circ} \mathrm{C}$, tartı: $6000 \mathrm{~g}$ (75p), boy:64cm (90-97p), baş çevresi:41cm (50-75p) bulundu. Ölçülen tansiyon değeri: 70/60mmHg, kalp atım sayısı: 168/dk. ritmik ve üfürüm yoktu. Solunum sayısı: 44/dk. ve solunum sesleri normaldi. Olgu kabul edildiğinde oksijen satürasyonu \%86 idi (3lt/dk oksijen alırken). Tedavide \%100 oksijen başlandı. Yapılan kan sayımında beyaz kan hücresi 17800/ $\mathrm{mm}^{3}$ (periferik yaymada \%75,4 lenfosit, \%11,6 nötrofil, \%5,6 monosit, \%2,8 eozinofil, \%4,6 bazofil) bulundu ve hemoliz bulgusu (periferik yaymada çekirdekli eritrositler, anizositoz, polikromazi, fragmante eritrositler) saptanmadi. Hemoglobin 9,5g/dL, hematokrit \%28,1, MCV 73,2fl, MCH 25,5pg, MCHC 34,8gr/dl, RDW \%14,9, trombosit sayıs1 456000/mm³ idi. Diğer biyokimyasal tetkikleri normaldi. İlk geldiğinde bakılan kan gazında pH: 7,4, pCO2: 39,6 mmHg, pO2: 98 mmHg, HCO3: 21.5mEq/1 ve methemoglobin düzeyi \%34,7 saptand. Çekilen P-A akciğer grafisi ve EKG normal olarak değerlendirildi. Hastaya lokal anestezik olarak prilokain verildiğinin öğrenilmesi, altta yatan solunumsal ve kardiyak bir nedenin bulunamaması ve kan gazında methemoglobin değerinin yüksekliği nedeniyle, ilaca bağlı methemoglobinemi düşünülerek metilen mavisi verilmesine karar verildi. Metilen mavisi $2 \mathrm{mg} / \mathrm{kg}$ oral verildi. Tedavinin birinci saatinde peroral bölge, üçüncü saatte ekstremite siyanozu kayboldu. Kontrol methemoglobin düzeyi \%2,7 olarak saptandı. İzlemde genel durumu iyi, siyanozu yoktu. Oral alımı iyi ve satürasyonları \%95 üzerinde olduğu için servisde 24 saatlik yatış sonrası şifa ile taburcu edildi.

\section{Tartışma}

Oksijene yanıt vermeyen siyanozlu bir olguda, dolaşım ve solunum sistemine ait bulguları yoksa öncelikle methemoglobinemi düşünülmelidir. İlk karşılaşılan klinik tablo periferik siyanozdur. Yaşamın ilk üç aylık döneminde, methemoglobin redüktaz aktivitesi düşük olduğu ve fetal hemoglobin daha kolay oksitlendiği için toksik maddelere bağlı methemoglobinemi riski daha çoktur [3]. Vakamızda, literatüre benzer olarak bu yaş grubunda görülmüştür. Methemoglobinemi kalıtsal veya edinsel nedenlerle gelişebilmektedir. Otozomal resesif geçişli dört tip herediter methemoglobinemi vardır. Bunlar çeşitli enzim sistemlerindeki doğuştan bozukluklara bağlı gelişir. En sık tip 1 görülür ve eritrositlerdeki sitokrom-b5 redüktaz enzim düzeyi düşüktür. Tip 2'de ensefalopati tablosu daha sık gelişebilir. Tip 3 eritrosit, lenfosit, granülosit ve trombositlerde enzim eksikliği ile seyreder. Tip 4'de ise kronik siyanoz mevcuttur [4-5]. Hastamızın aile taramasında methemoglobinemili bir olgu olmadığı belirtildi.

Bugüne kadar edinsel methemoglobinemi yaptığı bilinen birçok kimyasal madde veya ilaç bildirilmiştir. Bunlar arasında; nitritler, nitratlar, anilin, kloratlar, kininler, aminobenzenler, nitrobenzenler, nitrotoluenler, fenasetin, klorokin, dapson, fenitoin, sülfonamidler ve lokal anestezikler say1labilir [3]. Prilokain, amid lokal anesteziklerinde en düşük toksik potansiyele sahiptir; bununla birlikte, duyarlı hastalar prilokaine maruz bırakıldıklarında, özellikle de daha büyük dozlarda verildikleri zaman methemoglobinemi geliştirebilirler [6].

Prilokainin toksik plazma konsantrasyonu $>5 \mu \mathrm{g} / \mathrm{ml}$ 'dir ve çocuklar için prilokainin önerilen maksimum dozu 5 ila $7 \mathrm{mg} / \mathrm{kg}$ 'dır [7]. Prilokain, metaboliti olan o-toluidin ile methemoglobinemiye yol açabilen ve yaygın kullanılan bir lokal anesteziktir. Prilokainin yarı ömrü yaklaşık 55 dakika olup, ilaç alımından 20-60 dakika sonra methemoglobinemi gelişebilir. Bu olguda da sünnet amacıyla prilokain enjeksiyonu yapılmış ve operasyondan iki saat sonra siyanoz geliştiği gözlenmiş ve ölçülen methemoglobin seviyesinin ise \%34,7 saptanmıştır. Methemoglobinemi tanısı kanda MetHb düzeyinin ölçülmesi ile konulur. Uygulamada prilokainin enjektabl formu (Citanest, AstraZeneca, İstanbul, Türkiye) ve prilokain-lidokain (Emla, AstraZeneca, İstanbul, Türkiye) kremi kullanılmaktadır. Bizim olgumuzda enjektabl form kullanılmıştır. Terapötik dozlardaki (1-2 mg/kg) prilokain, genelde, siyanoza yol açmayacak kadar düşük düzeylerde methemoglobin oluşumuna neden olmakta doz arttıkça methemoglobinemi riski de artmaktadır. Ancak literatürde, olgumuzda olduğu gibi, terapötik dozda kullanım sonrası methemoglobinemi gelişimi bildirilmiştir. Bu nedenle çocuklarda özellikle ilk üç aylık dönemde bupivakain daha güvenilir bir lokal anesteziktir [7]. Methemoglobinemi, hayatı tehdit eden bir durum olduğundan, tanı ve tedavi yönünden acil durumdur. Doku oksijenizasyonu bozulur ve hipoksi gelişir. Methemoglobin düzeyi \%20'den düşükse genelde neden olan ilacın kesilmesiyle düzelme görülür. İlaca bağlı methemoglobinemi düşünüldüğünde, ilk planda ilacın verilmesi durdurulmalı ve imkân varsa vücuttan uzaklaştıılmalıdır. Oksidan ajanı takip eden saatlerde kan methemoglobin düzeyi \%20'den fazla ve hasta semptomatik ise veya asemptomatik bile 
olsa \%30'dan fazla ise tedavi düşünülmelidir. İlaca bağlı gelişen toksik methemoglobinemi tedavisinde ilk seçenek metilen mavisi infüzyonudur. Metilen mavisinin etkin olabilmesi ve eritrositlerde nikotin amid adenin dinükleotidin asıl kaynağı olan glikoliz döngüsünün işlemesi için mutlaka dekstroz verilmelidir. Daha yüksek konsantrasyonlarda ise metilen mavisi, 1-2 mg/kg dozunda, en az beş dakika süreyle intravenöz olarak kullanılabilir ve gerekirse bir saat sonra doz tekrarlanabilir. Maksimum kümülatif doz $7 \mathrm{mg} / \mathrm{kg}$ sınırını geçmemelidir [8]. Oral kullanımının da etkili olduğu bilinmektedir [9]. Bu olguda ise hastanemizde metilen mavisinin intravenöz formu bulunmadığı için $2 \mathrm{mg} / \mathrm{kg}$ tek doz oral metilen mavisi uygulandı. Metilen mavisi, kofaktör olarak NADPH kullanan ve sitokrom-b5 redüktaz enziminden ayrı olan bir başka redüktaz sistemini kullanarak methemoglobin düzeyini düşürür ve tedavinin en önemli bölümünü oluşturmaktadır. NADPH için normal heksozmonofosfat şantı gerektiğinden, glukoz 6 fosfat dehidrojenaz eksikliğinde metilen mavisi methemoglobinemiyi arttırır ve dispne, tremor, siyanoz ve hemolitik anemiye neden olabileceğinden kontrendikedir [3]. Hastamızda daha önce yenidoğan döneminde bakılan enzim düzeyinin normal olduğu belirtildi. Bu durumda metilen mavisi yerine askorbik asit kullanılabilir. Methemoglobin düzeyi \%70'in üstündeyse, ek olarak hiperbarik oksijen ve kan değişimine gerek olabilir [10]. Cerrahi uygulamalar sırasında komplikasyonlar olabilmekte, özelliklede lokal anestezi olarak kullanılan prilokain ve diğer ilaçlarla methemoglobinemi gelişebilmektedir [11].

\section{Sonuç}

Siyanoz ile başvuran dolaşım ve solunum sistem bulguları normal her hastada methemoglobinemi düşünülmeli ve mutlaka ayrıntılı ilaç kullanımı sorgulanmalıdır. Özellikle ülkemiz gibi sünnet oranının yüksek olduğu yerlerde, lokal anestezik ajanlar ile yapılan sünnet sonrası methemoglobin düzeyinin non-invaziv yöntemlerle belli bir süre izlenmesi olası ciddi sorunları önleyebilir [12]. Tedavide yaşamsal önemi olan metilen mavisinin hastanelerde zorunlu olarak bulunması gerekmektedir.

\section{Hasta Onayı/Patient's consent: Evet/Yes.}

Çıkar Çatışması/Conflict of interest: Yok/none

\section{Finansal Destek/Funding: Yok/none}

\section{Kaynaklar}

1. Wright RO, Lewander WJ, Woolf AD. Methemoglobinemia: etiology, pharmacology, and clinical management. Ann Emerg Med. 1999 Nov;34(5):646-56. PMID: 10533013.

2. Curry S. Methemoglobinemia. Ann Emerg Med. 1982 Apr;11(4):214-21. PMID: 7073040.

3. Liao YP, Hung DZ, Yang DY. Hemolytic anemia after methylene blue therapy for aniline-induced methemoglobinemia. Vet Hum Toxicol. 2002 Feb;44(1):19-21. PMID: 11824767.

4. George R. Honig. Hemoglobin Disorders. In: Behrman RE, Kliegman RM,Jenson HB (eds). Nelson Textbook of Pediatrics. 16 th ed. Philadelphia, W.B. Saunders Company, 2000. 1484p.

5. Svecova D, Bohmer D. Congenital and acquired methemoglobinemia and its therapy. Cas Lek Cesk. 1998 Mar 23;137(6):168-70. PMID: 9588101.

6. Taddio A, Stevens B, Craig K, Rastogi P, Ben-David S, Shennan A, et al. Efficacy and safety of lidocaine- prilocaine cream for pain during circumcision. N Engl J Med 1997 Apr 24;336(17):1197-201. PMID: 9110906.

7. Gunter JB. Benefit and risks of local anesthetics in infants and children. Pediatr Drugs. 2002;4(10):649-72. PMID: 12269841.

8. Tutak E. Prilokain enjeksiyonu sonrası akkiz methemoglobinemi gelişen bir yenidoğan olgusu. Çukurova Üniversitesi Tıp Fakültesi Dergisi, 2002;(27.2):145-8.

9. Karahan MA. Prilokain sonrası methemoglobinemi: Bir olgu sunumu. Harran Tip Fak Derg. 2011;(8):123-4.

10. Tabel Y. Sünnet öncesi uygulanan lokal prilokaine bağlı methemoglobinemi olgusu. Dicle Tip Dergisi. 2009;(36.1):53-55.

11. Özkan A. Bin dokuz yüz sünnet olgusunda komplikasyonların retrospektif incelenmesi. Konuralp Tıp Dergisi. 2012;(1):8-12.

12. Çağlar M, Alaçakır EN, Dursun O. Sünnet sırasında uygulanan prilokain anestezisi ile ilişkili methemoglobinemi. J Pediatr Emerg Intensive Care Med 2016;(3):36-38. doi: https://doi.org/10.4274/cayd.07279 